\title{
COMMENTARY
}

\section{AT1 receptor-associated protein and septic shock-induced vascular hyporeactivity: another 'magic bullet' in the pipe?}

\author{
Antoine Kimmoun ${ }^{1,2,3^{*}}$ and Bruno Levy ${ }^{1,2,3}$ \\ See related research by Mederle et al., http://ccforum.com/content/17/4/R130
}

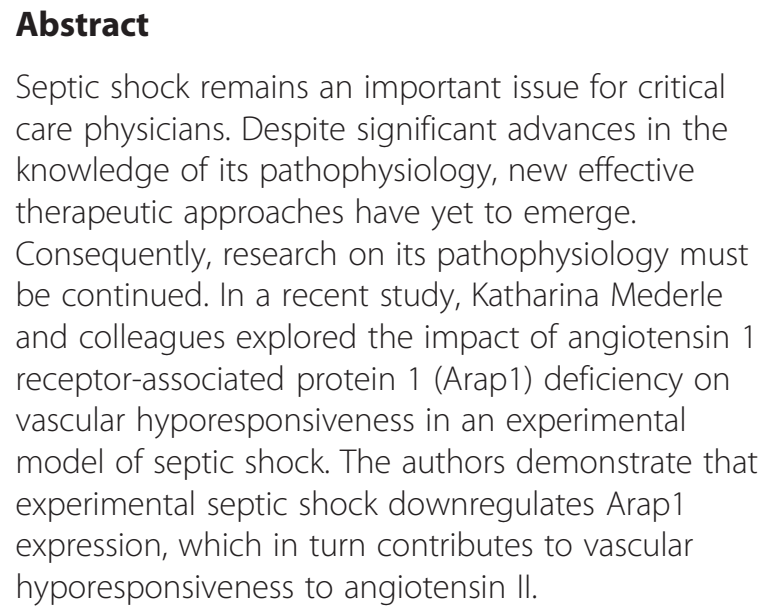

Septic shock is a persistent and non-resolved issue in intensive care units, with an increasing incidence rate of $15 \%$. The mortality rate from it, after having decreased thanks to the implementation of specific guidelines, is still $40 \%$ and thus of consequence. All recent clinical trials have returned negative results such that we now might not expect new efficient therapies to improve septic shock management. Etiological treatment (anti-infectious therapy, surgery), the excessive inflammation state, and multiple organ failure, including septic cardiomyopathy and vascular hyporeactivity, are the main aspects that remain to be improved.

Vascular hyporesponsiveness to vasopressors is a significant and independent prognostic factor of mortality

\footnotetext{
* Correspondence: a.kimmoun@chu-nancy.fr

${ }^{1} \mathrm{CHU}$ Nancy, Service de Réanimation Médicale Brabois; Pole Cardiovasculaire et Réanimation Médicale, Hôpital Brabois, 54511 Vandoeuvre les, Nancy, France

2INSERM U1116, Equipe 2, Faculté de Médecine, 54511 Vandoeurre les, Nancy, France

Full list of author information is available at the end of the article
}

involving several mechanisms and numerous cellular pathways and for which there is no new efficient and safe targeted therapy. The renin-angiotensin system plays a major role in vascular reactivity regulation in healthy patients. Constriction of vascular smooth muscle for vessel contractions involves synergistic processes leading to an increase in intracellular calcium. This increase is the result of neural or hormonal activation by ligands such as norepinephrine and angiotensin II. Although widely suspected, specific angiotensin II receptor involvement during septic shock has never been clearly assessed before the recent study by Mederle and colleagues [1].

In their present work, Mederle and colleagues aim to demonstrate that experimental sepsis induces down regulation of angiotensin 1 receptor-associated protein 1 (Arap1) expression, which contributes to hypotension through vascular hyporesponsiveness to angiotensin II [1]. In a previous study, the same team reported that Arap 1 in kidney vasculature is suppressed by angiotensin II. Widely distributed in the vascular system, Arap1 is a relevant choice to explore renin-angiotensin system involvement in septic shock [2].

In the new study, the authors show a drop in mean arterial pressure in Arap1-/- deficient mice compared to wild-type mice after lipopolysaccharide injection. A subsequently observed transient recovery of mean arterial pressure appears to be linked to the activation of the renin-angiotensin system. Addition of an inhibitor of angiotensin converting enzyme was found to suppress this short recovery, hence supporting this hypothesis. Moreover, both in vivo and in vitro Arap1 expression was significantly and deeply downregulated after lipopolysaccharide injection. In isolated perfused kidney, renal vascular resistance was reduced in response to incremental doses of angiotensin II in kidneys from Arap1-/- compared to wild-type mice. Surprisingly, 
renin secretion was enhanced in vivo in Arap1-/- mice, which is probably explained by systemic rather than direct effects of angiotensin II on renin-producing cells.

Finally, this work yields important key messages regarding angiotensin II pathophysiology during septic shock. During endotoxemia, Arap1 expression is downregulated, which contributes to vascular hyporesponsiveness to angiotensin II.

This significant pathophysiological study raises many questions. Importantly, the impact of Arap1 deficiency on survival of Arap1-/- compared to wild-type mice during endotoxemia is unknown. This information could clarify the importance of Arap1 deficiency in sepsis compared to other mechanisms (ATP-sensitive $\mathrm{K}+$ channel activation, nitric oxide, peroxynitrite, and so on) [3]. Moreover, the downregulation of Arap1 gene expression (protein expression was not confirmed in this study) may be an adaptive mechanism during endotoxemia. Hagiwara and colleagues [4] previously demonstrated for other specific angiotensin II receptors that a type 1 angiotensin II receptor antagonist reduces lung damage in an experimental septic shock model. The pro-inflammatory effect of angiotensin II may be counteracted by inhibition of Arap1. Thus, it is unknown whether Arap1 deficiency is just a protective mechanism.

Further studies are needed to determine the impact on survival and the importance of Arap1 deficiency compared to other mechanisms involved in vascular hyporesponsiveness. This new pathophysiological means of vascular hyporeactivity could represent a future area of research, with many therapeutic implications for the management of refractory septic shock. On the other hand, numerous pathways and molecules have been implicated in vascular hyporesponsiveness induced by sepsis. Despite very convincing pre-clinical data, none of the latter, including knock-out/overexpressed animal experiments, have demonstrated significant effects in septic shock (nitric oxide inhibitors, activated protein $C$ ). Consequently, we must be creative in filling the gap between pathophysiological knowledge and evidence from animal models and almost consistently failed clinical trials.

\section{Abbreviation}

Arap1: Angiotensin 1 receptor-associated protein 1.

\section{Competing interests}

The authors declare that they have no competing interests.

\section{Author details}

${ }^{1} \mathrm{CHU}$ Nancy, Service de Réanimation Médicale Brabois; Pole Cardiovasculaire et Réanimation Médicale, Hôpital Brabois, 54511 Vandoeuvre les, Nancy, France. ${ }^{2}$ INSERM U1116, Equipe 2, Faculté de Médecine, 54511 Vandoeuvre les, Nancy, France. ${ }^{3}$ Université de Lorraine, 54000, Nancy, France.

Published: 18 Nov 2013

References

1. Mederle K, Schweda F, Kattler V, Doblinger E, Miyata K, Höcherl K, Oike Y, Castrop H: The angiotensin II AT1 receptor-associated protein Arap1 is involved in sepsis-induced hypotension. Crit Care 2013, 17:R130.

2. Doblinger $E$, Hocherl $K$, Mederle $K$, Kattler V, Walter S, Hansen PB, Jensen B, Castrop H: Angiotensin AT1 receptor-associated protein Arap1 in the kidney vasculature is suppressed by angiotensin II. Am J Physiol Renal Physiol 2012, 302:F1313-F1324.

3. Kimmoun A, Ducrocq N, Levy B: Mechanisms of vascular hyporesponsiveness in septic shock. Curr Vasc Pharmacol 2013, 11:139-149.

4. Hagiwara S, Iwasaka H, Hidaka S, Hasegawa A, Koga H, Noguchi T: Antagonist of the type-1 ANG II receptor prevents against LPS-induced septic shock in rats. Intensive Care Med 2009, 35:1471-1478.

$10.1186 / \mathrm{cc} 13116$

Cite this article as: Kimmoun and Levy: AT1 receptor-associated protein and septic shock-induced vascular hyporeactivity: another 'magic bullet' in the pipe? Critical Care 2013, 17:179 